5. Розин, В. М. Сущность и тайна музыки // Philharmonica. International Music Journal. 2014. - № 2. - C. 194-218. - DOI: 10.7256/1339-4002.2014.3.13588.

6. Зильберквит, М. А. Рождение фортепиано. - 2-е изд. - Москва : Дет. лит-ра, 1984. - 64 с.

7. Алексеев, А. Методика обучения игре на фортепиано. - Москва : Музыка, 1978. - 288 с.

Olga V. Goloshchapova

Altai State Institute of Culture (Barnaul, Russia) ola-altai@mail.ru

\title{
THEORETICAL ASPECTS OF UPBRINGING A SCHOOLCHILD'S MUSICAL INTEREST IN THE CONTEXT OF ARTISTIC AND AESTHETIC EDUCATION
}

\begin{abstract}
The paper briefly outlines a significance and function of musical art in human life. In the author's opinion, music has rich pedagogical opportunities, it can be considered as a mean for pedagogical affecting on a personality's emotional, ethic qualities, as well as on cognitive and motivational processes. The clarified version of "musical interest" concept is given. The author describes peculiarities and difficulties of developing musical interests of a students of the today's Russian art school in the context of a personality's common artistic and aesthetic growth. The set of comfortable pedagogical conditions for improvement of a level of musical education of a junior schoolchild, for development a personality's ability to perception and comprehension of music is offered.

Keywords: music, a student of children's art school, building of a junior schoolchild's personality's qualities, musical interest, a sense of musical art, comprehension of a musical piece, pedagogical conditions for perception of music, a personality's artistic and aesthetic growth.
\end{abstract}

УДК 378.14:792.92:37.013.42

DOI: $10.32340 / 2414-9101-2019-1-67-72$

В. Л. Русинов, профессор, заслуженный работник культуры Российской Федерации Восточно-Сибирский государственный институт культуры (Улан-Удэ, Россия) rina.rubin@yandex.ru

\section{ЛЕТНЯЯ ТВОРЧЕСКАЯ ШКОЛА КАК ПЛОЩАДКА ПРАКТИКО-ОРИЕНТИРОВАННОГО ОБУЧЕНИЯ СТУДЕНТОВ - РЕЖИССЁРОВ ПРАЗДНИКОВ}

Аннотация. Обобщен авторский опыт воспитания профессионально и личностно значимых качеств у будущих режиссёров театрализованных представлений средствами инклюзивных образовательных программ в рамках многолетнего (2015-2019 гг.) специализированного проекта Байкальской летней творческой школы, организуемой студентами кафедры режиссуры эстрады и театрализованных представлений Восточно-Сибирского государственного института культуры (г. Улан-Удэ, Россия). Охарактеризованы ключевые особенности формирования организационных и сценарно-постановочных компетенций обучающихся, навыков работы в творческом коллективе.

Ключевые слова: театрализация, инклюзия, игровая деятельность, лица с ограниченными возможностями здоровья, жанр ландшафтного действа, обучаюшиеся коррекционных школ, внеучебная деятельность обучающихся, арт-терапия, театр-лаборатория.

Педагогическим сообществом давно воспринят факт, что процесс обучения должен иметь практическую направленность. Не всем это удается в равной мере, тем более, что современное развитие науки и общественной практики ведут к росту объема учебной информации, в то время, как сроки ее усвоения перманентно сокращаются. Автор статьи считает, что одним из путей 
решения проблемы является расширение внеучебной деятельности обучаемых, направленной на практическое освоение основ профессии. В начале XXI века таким решением было создание театра «Душа Байкала», в процессе реализации мероприятий которого произошло профессиональное становление многих известных сейчас в республике деятелей праздничной культуры. Сейчас аналогичную роль играет проект Байкальской летней творческой школы для одаренных детей с нарушениями слуха.

Данный проект появился в результате длительного сотрудничества Восточно-Сибирской академии культуры и искусств со Специальной (коррекционной) общеобразовательной школойинтернатом для глухих и слабослышащих детей. Началось это сотрудничество в 2010 году, когда студентов кафедры «Режиссура эстрады и театрализованных представлений» курса Русинова В. Л. попросили провести там два шефских концерта. Успех мероприятий обусловил приглашение помочь в проведении новогоднего представления 2011 года. С этого времени началось регулярное творческое общение студентов академии и учеников школы-интерната.

Результатом стали творческие показы на I Республиканском конкурсе «Воспитатель года» среди коррекционных школ Республики Бурятия. Для зонального конкурса инвалидов по слуху в мае 2011 года в Абакане были созданы презентация «Теневой театр» и миниатюры, исполнители которых и постановщики, студентки Анита Малахова и Оксана Цыбикова, стали лауреатами конкурса и участниками III Всероссийского конкурса концертных программ, посвященного 85-летию Всероссийского общества глухих, проходившему в Москве, а позже - приняли участие в Юбилейном концерте в Сочи.

В ноябре этого же года студенты провели мастер-класс по драматерапии с инвалидами по слуху на Всероссийской научно-практической конференции «Роль арт-терапии в психофизическом оздоровлении общества и человека».

Так постепенно вызревал проект инклюзивного образовательно-воспитательного пространства, воплотившийся в создании театра-лаборатории мимики и жеста «Голос тишины» как площадки совместного творчества детей с нарушениями слуха и студентов кафедры режиссуры эстрады и театрализованных представлений под руководством В. Л. Русинова с целью социализации инвалидов по слуху и обучения специалистов творческих специальностей работе с детьми инвалидами [1, с. 60-61].

Опыт театра-лаборатории воспроизведен на разных уровнях: локальном - в рамках культурно-просветительских мероприятий, повышения квалификации педагогов дополнительного образования и учителей коррекционных школ; в муниципальном - в рамках городских мероприятий: театрализованных представлений, конкурсов, конференций по арт-педагогике; региональном домах культуры Всероссийского общества глухих, федеральном - в сети Интернет, печатных изданиях, российских конкурсах.

В 2012-2014 гг. коррекционная школа стала базой, где студенты под руководством В. Л. Русинова проходили производственную и педагогическую практику, готовя проведение праздников «Сагалгаан», «Масленица», «8 марта», «День знаний», «День защиты детей». Студентка Анита Малахова была принята в школу преподавателем дополнительного образования, стала уникальным специалистом, так как воспитывалась в семье глухих и в совершенстве владеет жестовой речью, является сертифицированным сурдопереводчиком.

В 2013 году состоялся набор следующего курса, и уже в сентябре студенты и учащиеся коррекционной школы выступили иллюстраторами доклада В. Л. Русинова «Арт-терапия как инновационное направление в развитии сферы образования, науки и искусства», прочитанного на конференции «Драматерапия в инклюзивном образовании».

В 2015 году для участия во Всероссийском конкурсе в Екатеринбурге ими был подготовлен полномасштабный театрализованный концерт «Бурятия - и земля легенд», исполнители которого - ученики коррекционной школы и члены республиканского отделения общества глухих, были удостоены лауреатского звания [2, с. 101] .

Параллельно проводилась работа над материалом представления по мотивам повести Р. Киплинга «Маугли». Премьера спектакля «Мы с тобой одной крови» состоялась на сцене институтского концертно-театрального центра «Феникс» 15 мая 2013 года. Зрителями были учащиеся коррекционных школ республики, их педагоги и родители, студенты и преподаватели ака- 
демии. Интерес к спектаклю был настолько велик - зал на 350 мест был переполнен - что пришлось повторять показ. Инклюзивный проект получил широкий общественный резонанс.

В 2015 году студенты курса В. Л. Русинова участвовали в организации и проведении республиканского конкурса «Лучший воспитатель коррекционной школы», республиканского фестиваля детского творчества «Весенний перезвон» для детей с ограниченными возможностями здоровья, проходившем в районном доме культуры поселка Турунтаево.

Уникальный опыт театра-лаборатории мимики и жеста «Голос тишины»-инновационной модели инклюзивного образования и творческого развития детей с нарушениями слуха послужил основой и получил дальнейшее развитие в проекте Байкальской летней творческой школы, участниками которой стали студенты академии и ученики коррекционной школы, а также дети с ограниченными возможностями, обучающиеся в детских школах искусств и средних образовательных учреждениях.

Решено было претендовать на грантовую поддержку Министерства культуры Российской Федерации в рамках проекта для молодых дарований с ограниченными возможностями по здоровью «Открытый мир творчества». Грант был выигран и началась организационная работа: формирование состава учредителей, которыми стали Министерство культуры Российской Федерации, Восточно-Сибирская государственная академия культуры и искусств, Специальная (коррекционная) общеобразовательная школа - интернат I-II вида, локализованная в столице республики, городе Улан-Удэ.

Для подготовки и проведения школы был создан организационный оргкомитет, в который вошли со стороны академии: проректор по учебной работе, кандидат физико-математических наук, доцент, председатель Управляющего совета коррекционной школы Н. Б. Цыренжапов, от кафедры «Режиссура эстрады и театрализованных представлений» профессор В. Л. Русинов, заведующие кафедрами дизайна, физического воспитания, юристы и экономисты. От коррекционной школы в оргкомитет вошли директор Н. В. Норбоева, заместитель директора С. В. Очирова, педагоги-воспитатели, сурдопедагоги, учителя-дефектологи Улан-Удэ и Иркутска.

Было обеспечено информирование о проекте управлений культуры и образовательных учреждений субъектов Российской Федерации.

Целью проведения школы стало выполнение Указа Президента Российской Федерации от 7 мая 2012 г. № 597 «О мероприятиях по реализации государственной социальной политики». Для достижения данной цели были поставлены следующие задачи: выявление художественно одаренной молодежи с ограниченными физическими возможностями, в том числе маломобильных; обеспечение соответствующих условий для их образования, творческого развития, социальной адаптации; осуществление доступа к ценностям искусства людей с ограниченными физическими возможностями; а также подготовка творческих кадров в сфере культуры и искусства; привлечение общественности и широкого круга заинтересованных лиц, представителей различных общественных организаций, специализирующихся на работе с инвалидами и маломобильными группами граждан к участию в культурных событиях.

Особенностью формата проекта стало выявление и поддержка одаренных детей с нарушениями слуха, развитие их творческих способностей средствами театральной терапии, развитие организаторских и коммуникативных способностей участников через разработку и создание творческих работ. Практическое обучение было направлено на развитие духовно-нравственного воспитания, креативного мышления, инновационного потенциала и нестандартного подхода к выполнению поставленных задач.

Базой для проведения школы был выбран спортивно-оздоровительный лагерь института, расположенный в поселке Энхалук на берегу озера Байкал. Были разработаны программа школы, ее логотип, сочинены сценарий и гимн, зафиксированный в инструментальной аудиозап иси. При формировании программы необходимо было учесть не только творческие и воспитательные задачи, но также тщательно продумать организационную составляющую, удовлетворяющую гигиеническим, рекреационным, медицинским требованиям, организовать систему четырехразового питания, обеспечить участников необходимыми методическими, дидактическими и расходными материалами, в объемах, соответствующих сценарию проведения мероприятий проекта. 
Основными направлениями творческих занятий были установлены: основы актёрского мастерства, основы пластики и сценического движения, хореография, декоративно- прикладное искусство и живопись, дизайн костюма и аквагрим, телесно-оздоровительные практики восточной медицины.

Для проведения творческих занятий были приглашены ведущие преподаватели высших учебных заведений, деятели культуры и искусства, специалисты по работе с детьми с ограниченными возможностями по слуху: заслуженный артист России, заведующий труппой Государственного академического театра Бурятской драмы имени Хоца Намсараева Дамба Бочиктоев, народный художник России, член Союза дизайнеров, член Союза художников Российской Федерации, профессор кафедры декоративно-прикладного искусства, лауреат Золотой Пушкинской медали Светлана Ринчинова, Почетный работник общего образования Российской Федерации Сэсэгма Очирова, руководитель методического объединения учителей-дефектологов Аюна Соктуева, директор института режиссуры актерского и изобразительного искусства, профессор Виктор Столбовский, заслуженный работник культуры Российской Федерации, лауреат премии «Теффи - регион», профессор кафедры «Режиссура эстрады и театрализованных представлений», заслуженный работник культуры Российской Федерации, лауреат национальной премии «Грани театра масс» Ольга Александровна Герасимова. Руководителем проекта был назначен профессор кафедры «Режиссура эстрады и театрализованных представлений», заслуженный работник культуры Российской Федерации, лауреат премии правительства Российской Федерации В. Л. Русинов.

Проект получил юридическую поддержку: юридические консультации, организационнотехнические работы по исполнению Договора, сопровождение договоров с контрагентами по документации и отчетности. Приглашенным специалистам и участникам летней школы был обеспечен прием и созданы необходимые условия для участия в мероприятиях, разработана, организована и обеспечена логистика, техническое оснащение необходимым светозвуковым оборудованием: 6 прожекторов мощностью 1000 ВТ, 2 активные колонки мощностью 300 ВТ, 3 микрофона 120 Гц, организованы аудио- и видеозаписи проекта (не для коммерческого использования).

Первая летняя школа состоялась в июне 2015 года. В ее работе приняли участие 50 школьников, 19 студентов и 5 преподавателей Академии культуры и искусств, 6 преподавателей Специальной (коррекционной) общеобразовательной школы из Улан-Удэ, 1 преподаватель аналогичного учебного заведения из города Иркутск.

В программу школы вошли 15 творческих мастерских и 5 творческих встреч с деятелями культуры и искусств. Важно, что все творческие занятия преследовали конкретную цель создания необходимых условий для осуществления сквозного интерактивного анимационно-ландшафтного действа «Сказание предков». Героями этого театрализованного действа были тотемные символы разных бурятских родов: Хозяин Воды, Праматерь Лебедь, Праотец Бык, Хозяин Гор, Черный Дух, роли которых играли студенты. Каждого героя окружала его свита, которую составляли ученики коррекционных школ. Главные герои выступали в масках-костюмах из спектакля В. Л. Русинова «Покровители», дети же готовили свои маски и костюмы самостоятельно в ходе творческих занятий. Сценарий действа включал шествия, церемонии и ритуалы, четыре квеста, театрализованные мини-представления, а завершался каждый день театрализованным подведением итогов у ночного тотемного костра. Публикацией результатов школы стала презентационная акция флэш-моб на центральной площади города. Итогом занятий по декоративно-прикладному искусству и живописи, кроме подготовки масок и костюмов, стала выставка «Байкальский вернисаж», на которой были представлены рисунки и поделки ребят из травы, цветов, шишек, камней и ракушек.

Кроме вышеуказанного, программа школы включила два круглых стола на темы «Выявление, развитие и поддержка молодых дарований с ограниченными возможностями здоровья» и «Совершенствование коммуникативной деятельности детей с нарушениями слуха посредством АРТ-терапии». В работе круглых столов приняли участие представители Министерства образования и науки Республики Бурятия, представители Бурятского регионального отделения Всероссийского общества глухих, специалисты по работе с детьми с ограниченными возможностями по 
слуху, ведущие преподаватели высших учебных заведений, деятели культуры и искусства и студенты академии. Участники круглого стола были единодушны в положительной оценке проекта школы, отметив, что летняя творческая школа для детей с ограниченными возможностями по слуху стартовала впервые и в регионе подобные мероприятия для детей с нарушениями слуха не проводились. Участники проекта обобщили следующие результаты:

- программа школы построена с учетом оздоровительного, рекреационного и общепознавательного компонента;

- эффективно используется технология творческих мастерских;

- выбранные методики, формы и средства обучения высоко результативны;

- применяемая в школе образовательная технология концентрированного обучения позволяет повысить уровень качества освоения изучаемого материала и способствует решению системы задач, поставленных перед участниками;

- в процессе реализации проекта школы проводилась целенаправленная работа по обучению детей общению с природой, то есть осуществлялось экологическое воспитание;

- школа способствует развитию творческих способностей детей с нарушениями слуха;

- участие в работе школы способствовало обмену опытом и расширению межрегиональных связей, дальнейшему образовательному, научному и творческому сотрудничеству.

Позитивный опыт проведения летней школы обусловил дальнейшую реализацию проекта: в 2016 году его содержанием стало действо «Мы с тобой одной крови», основанное на инклюзивном спектакле театра-лаборатории «Голос тишины», в 2017 - «Изумрудный город против Бастинды и другие приключения озерного люда», сценаристом и постановщиком которого выступила студентка выпускного курса заочной формы обучения Анна Емельянова (руководитель В. Л. Русинов). В 2018 году цементирующим деятельность летней школы действом стал парафраз на популярный мультипликационный фильм «Кунг-Фу Панда», режиссировал который преподаватель курса В. Л. Русинова Ф. В. Степанов.

Школы 2016-2018 гг. строятся по оправдавшему себя структурному принципу, используют позитивные жанрово-тематические наработки первой школы. Сложность данного проекта обусловлена несколькими особенностями. Во-первых, это его адрес - детская аудитория, причем не гомогенная, а состоящая из здоровых детей и детей с ограниченными возможностями. Поэтому задачи, поставленные и решаемые в процессе реализации проекта, не ограничиваются только сценарными и режиссерско-постановочными, но охватывают широкий спектр психологопедагогических проблем. Во-вторых, количество участников, обычно превышающее 80 человек, в третьих, - значительный временной масштаб. Следовательно, необходимо так выстроить действие, чтобы на всем протяжении пяти дней оно не замедлялось, и участники школы сохраняли бы к нему непреходящий интерес. Для этого действие должно постоянно сопрягаться с контрдействием, для нейтрализации которого участники школы должны предпринимать собственные шаги.

Проект реализуется в жанре ландшафтного действа, значительно менее распространенного, чем такие жанры праздничной культуры, как праздник, митинг, театрализованное представление. Сложность данного жанра заключена в необходимости непосредственной связи происходящих событий с конкретной природной площадкой. Более того, временные рамки школы диктуют необходимость включения нескольких разных площадок, что также динамизирует происходящий процесс. Однако временная протяженность школы диктует необходимость полижанровости, когда ландшафтное действо включает несколько типов праздничных действ: театрализованные представления на нестандартных площадках, шествия, обряды поклонения огню, Байкалу, кормления воды, церемонии открытия и закрытия Школы, церемонии награждения победителей, дефиле, театрализованные игровые программы, а также квест-игры и мастер-классы.

Сквозная линия ландшафтного действа формируется театрализованным представлением на выбранную тему, причем известные сюжеты развиваются и переосмысливаются сценаристом в соответствии с задачами проекта.

Студенты учатся постановочной и организационной работе, работе в коллективе, организации творческого процесса и критическому анализу его реализации, гибкому реагированию 
на возникающие трудности, замечания и предложения творческого руководителя. Сложность заключается в воспитании творческой выносливости, когда после долгого и трудного дня нужно проводить анализ выполненного, а ранним утром - планерки и репетиции. Однако несмотря на трудности, студенты после завершения школы уже планируют участие в следующей.

Вышеизложенное позволяет заключить, что данный проект имеет будущее: создалась команда единомышленников из преподавателей и студентов, детей и учителей, деятелей культуры и искусств для его продолжения и расширения, что позволит:

- расширить формы инклюзивного образования, нейтрализующего изолированность от общества детей с нарушениями слуха;

- развивать самооценку детей с нарушениями слуха, их физическое и эмоциональноличностное развитие через включение в успешную деятельность;

- формировать толерантное общество и социальную ответственность здоровых людей через творческую коммуникацию детей с ограниченными возможностями по слуху со студентами и преподавателями;

Практика театра-лаборатории и Байкальской летней творческой школы, выводы специалистов по работе с детьми показывают, что при нарушениях слуха использование театрализованоигровой деятельности в различных ее формах дает положительные результаты как в формировании познавательной, двигательной, так и в развитии эмоциональной сферы [3, с. 81]. Но что еще более важно - оказывает лечебное воздействие, является способом профилактики и коррекции отклонений в развитии.

\title{
Список литературы
}

1. Кузнецова, О. 3. Театр-лаборатория как средство формирования инклюзивного воспитания / О. З. Кузнецова, В. Л. Русинова // Воспитательное пространство образовательного учреждения : сб. матер. междунар. науч.-практ. конф. (Улаан-Батаар, Монголия; 22 марта 2013 г.).Улаан-Баатар : [Б. и.], 2013. - С. 59-63.

2. Русинов, В. Л. Практика создания инклюзивного пространства средствами театрализованоигровой деятельности / В. Л. Русинов, О. А. Русинова // Организация инклюзивного образовательного пространства: состояние и перспективы : сб. матер. междунар. науч.-практ. конф. (УланУдэ, 13-15 июня 2017 г.). - Улан-Удэ : Изд-во Вост.-Сиб. гос. ин-та культуры, 2017. - С. 100-105.

3. Русинова, О. А. Воспитание творческого мышления в образовательном пространстве ВУЗа / О. А. Русинова, В. Л. Русинов // Воспитательное пространство образовательного учреждения : сб. матер. междунар. науч.-практ. конф. (Улаан-Батаар, Монголия; 22 марта 2013 г.). - УлаанБаатар : [Б. и.], 2013. - С. 79-82.

Viktor L. Rusinov

Professor, Honored Worker of Culture of the Russian Federation East-Siberian Institute of Culture (Ulan-Ude, Russia) rina.rubin@yandex.ru

\section{A SUMMER CREATIVE SCHOOL - A PLATFORMOF PRACTICE-ORIENTED EDUCATION FOR INTENDED EVENT DIRECTORS}

\begin{abstract}
The article outlines the author's experience in building professionally and personally important features of an intended event director by means of inclusive educational program within the frames of Baikal Summer Creative School, a long-time (2015-2019) project run by students of Department of Variety-Art and Theatrical Performance Making of the East-Siberian State Institute of Culture (Ulan-Ude, Russia). The author outlines the key aspects of building organizational competences, upbringing abilities to scriptwriting and co-working in a creative team.

Keywords: theatricalization, inclusive education, game activity, persons with disabilities, a genre of landscape action, students from special schools, students' extra-curricular activities, art therapy, a theatre-lab.
\end{abstract}

